\title{
Guy Peeters, La Justice belge contre le sieur Victor
}

\section{Hugo}

\section{michel brix}

\section{(2) OpenEdition}

10 Journals

\section{Édition électronique}

URL : https://journals.openedition.org/studifrancesi/46104

DOI : 10.4000/studifrancesi.46104

ISSN : 2427-5856

Éditeur

Rosenberg \& Sellier

\section{Édition imprimée}

Date de publication : 1 octobre 2007

Pagination : 466

ISSN : 0039-2944

\section{Référence électronique}

michel brix, "Guy Peeters, La Justice belge contre le sieur Victor Hugo », Studi Francesi [En ligne], 152 (LI | II) | 2007, mis en ligne le 30 novembre 2015, consulté le 24 novembre 2021. URL : http:// journals.openedition.org/studifrancesi/46104; DOI : https://doi.org/10.4000/studifrancesi.46104

Ce document a été généré automatiquement le 24 novembre 2021.

\section{(c) (i) (9)}

Studi Francesi è distribuita con Licenza Creative Commons Attribuzione - Non commerciale - Non opere derivate 4.0 Internazionale. 


\title{
Guy Peeters, La Justice belge contre le sieur Victor Hugo
}

\author{
michel brix
}

\section{RÉFÉRENCE}

GUY PEETERS, La Justice belge contre le sieur Victor Hugo, Paris, Honoré Champion, «Romantisme et modernités», 2005, pp. 182.

«Je ne croyais pas qu'il pût y avoir quelque chose au-dessous de la magistrature française. Hé bien, il y a la magistrature belge». Ce constat, qu'on pourrait croire de Baudelaire, vient en fait de Hugo: il est exprimé dans une lettre à Paul Meurice du 29 juillet 1871 et fait allusion à de récents démêlés du poète avec la justice belge. En mai 1871, les Versaillais avaient, à Paris, écrasé les Communards. Victor Hugo résidait alors à Bruxelles, dans une maison située 4, place des Barricades. Le 26 mai, il écrit une lettre à L'Indépendance belge, que le journal publie le 27 et dans laquelle l'auteur des Contemplations offre aux Communards l'asile de sa propre maison. C'était prendre à rebours les ministres de Léopold II, qui venaient d'assimiler les Communards à des criminels et leur avaient, à ce titre, refusi le statut de réfugiés politiques. L'opinion bruxelloise allait d'ailleurs manifester violemment à Hugo sa disapprobation pour les propos généreux insérés dans L'Indépendance belge. Dans la nuit du 27 au 28 mai, le 4 de la place des Barricades fut en effet visé par un caillassage, aux cris de «Mort à Victor Hugo!» et «Mort à Jean Valjean!». La plainte de l'écrivain auprès de la police aboutit à un ordre d'expulsion visant... le poète lui-même, accusé de troubler l'ordre public! Hugo dut partir, avec sa famille, dès le 31 mai, et gagner le grand-duché de Luxembourg. Quant à l'enquête sur les événements de la place des Barricades, elle traîna en longueur, puis s'enlisa définitivement, malgré les protestations indignées de Hugo et malgré aussi - à moins qu'il ne faille écrire: à cause de - la révélation, par un journal bruxellois, que le fils du ministre belge de l'Intérieur, Kervyn de Lettenhove, figurait parmi les assaillants. D'où la fureur de l'écrivain, exprimée sans fard à Paul Meurice le 29 juillet suivant. - Guy Peeters a rouvert le dossier de cette instruction 
judiciaire bâclée et en a notamment consulté les pièces officielles, «qui dormaient toujours dans une farde oubliée» (p. 8). Il relève ainsi tous les atermoiements et les dysfonctionnements (le mot est récent, mais pas la réalité qu'il recouvre) qui ont conduit l'enquête dans l'impasse.

2 Au demeurant, Hugo était, depuis le mois de dicembre 1851, l'objet d'une attention soutenue de la part de la sécurité publique belge. Peeters a parcouru tous les rapports qui ont été écrits sur l'auteur des Misérables, ainsi que quelques dossiers connexes (notamment ceux qui étaient ouverts aux noms de Jules Hetzel et de Henri Rochefort). Il en a tiré des informations inédites, qui éclairent par exemple d'un jour nouveau les relations de Hugo et de ses fils avec la ville de Spa.

3 Contrairement à ce qu'on aurait pu craindre, l'ouvrage de Peeters n'est pas manichéen et ne présente pas de façon caricaturale le gentil poète versus la méchante justice des bourgeois belges. Certes, plusieurs magistrats ou ministres d'Outre-Quiévrain se sont tristement distingués lors de l'affaire de la place des Barricades, mais - sur un plan plus général - Peeters restitue bien la situation difficile où se trouvait en l'occurrence la Belgique. Celle-ci pouvait légitimement hésiter devant la perspective de servir de base arrière aux républicains et aux socialistes français - ce qui aurait déplu au puissant voisin et n'était pas sans risque pour ses propres institutions. D'un autre côté, il ne fallait pas non plus avoir l'air d'abdiquer toute autonomie. Par surcroît, les réfugiés politiques français n'étaient pas dépourvus d'arrière-pensée concernant la Belgique. Un document très instructif, à cet égard, est cité dans l'ouvrage: il s'agit de la retranscription du dialogue entre Hugo et son fils Charles, où l'auteur des Misérables préconise que Napoléon III envahisse et annexe la Belgique, «région» que Hugo met sur le même pied que la Franche-Comté ou l'Alsace (voir pp. 84-85).

4 Deux détails, pour terminer: p. 39, on ne sait à quoi renvoie la «note 90»; p. 157, il faut sans doute lire «Sans précédent» et non «Un précédent». 